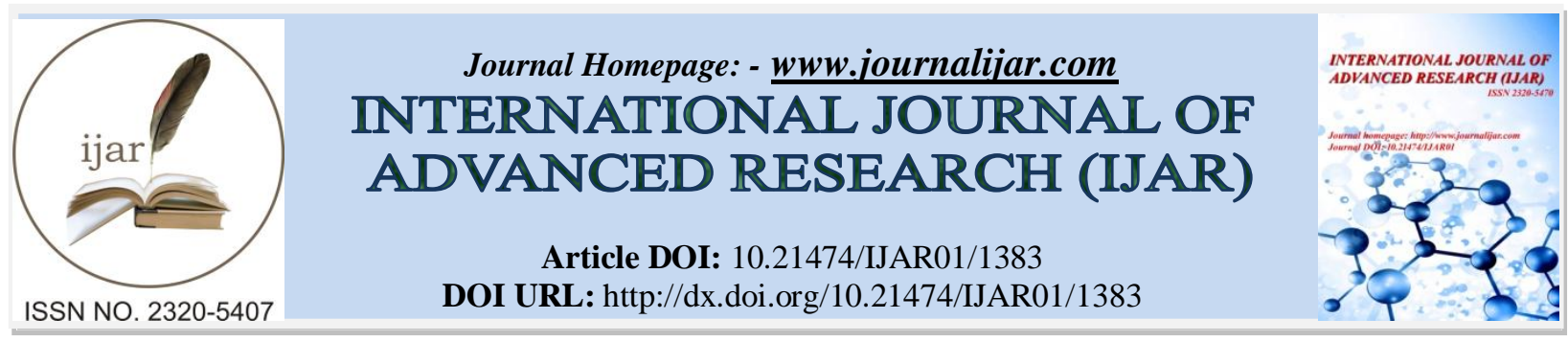

RESEARCH ARTICLE

\title{
IN VIVO ELIMINATION OF ARSENIC THROUGH LACTOBACILLUS SPOROGENES.
}

\author{
Ranjit Kumar $^{1 *}$, Roushan Kumari ${ }^{1}$, Arun Kumar ${ }^{1}$, Vikash Kumar Ravi ${ }^{2}$ and Md Ali ${ }^{1}$ \\ 1. Mahavir Cancer Institute \& Research Centre, Phulwarisharif, Patna (Bihar), India. \\ 2. Veer kunwar Singh University,Ara.
}

\section{Manuscript Info}

Manuscript History

Received: 14 June 2016

Final Accepted: 19 July 2016

Published: August 2016

Key words:-

Lactobacillus, PCT, DCT, arsenic.
Abstract

Groundwater arsenic contamination is a global phenomenon affecting more than 70 countries on six continents. Arsenic is one of the more ubiquitous minerals in the Earth's crust. It is also concentrated in hydrous iron oxides. Arsenic can be easily solubilized in ground waters depending on $\mathrm{pH}$, redox conditions, temperature and solution composition. Therefore the study is designed to evaluate in vivo effect of Lactobacillus sporogenes on arsenic degradation in mice. Mice were administered arsenic for four weeks followed by 8 weeks administration of Lactobacillus. Arsenic causes increased level of urea and uric acid. While urea and uric acid level were restored effectively in Lactobacillus administered group. Glomerulus and Bowmens capsule were restored effectively in eight weeks Lactobacillus administered group. Cytoplasm of PCT and DCT were restored effectively after eight weeks of Lactobacillus administration. Therefore it is concluded that Lactobacillus causes in vivo elimination of arsenic from mice. It acts well against arsenic induced toxicity in mice and restores biochemical parameters effectively. It also maintains normal morphology of kidney tissues. Lactobacillus reduces nephrotoxicity caused by arsenic exposure effectively. In this way it acts effectively against arsenic induced toxicity. Therefore it is one of the most effective antidote against arsenic induced toxicity.

Copy Right, IJAR, 2016,. All rights reserved.

\section{Introduction:-}

Ground water arsenic contamination had already been reported in 20 countries out of which major incident were from Asia. Arsenic-related groundwater problems have emerged in different Asian countries, including new sites in China, Mongolia, Nepal, Cambodia, Myanmar, Afghanistan and Pakistan ${ }^{1}$. Groundwater arsenic contamination is a global phenomenon affecting more than 70 countries on six continents. The Ganga-Meghna-Brahmaputra plain is extensively populated. These populations intensively exploits groundwater resources, experiencing a myriad of environmental impacts associated with local, regional, and global issue ${ }^{2}$. Arsenic contamination of groundwater in the Bengal Basin has been called 'the largest mass poisoning in human history ${ }^{3}$. In south Asia, enrichment of arsenic in groundwater possesses a serious health threat not only limited to human being but also accumulate in plant and fish ${ }^{4}$. Arsenic contamination of ground water may occur in two ways: anthropogenic activities and aquifer naturally contain. Ground water contamination cross the permissible limit of WHO $(0.01 \mathrm{mg} / \mathrm{L})$, excess arsenic has been detected in drinking water supply in many country about 200 million people under risk ${ }^{5}$. Arsenic is one of the more ubiquitous minerals in the Earth's crust. It is also concentrated in hydrous iron oxides. Arsenic can be easily 
solubilized in ground waters depending on $\mathrm{pH}$, redox conditions, temperature, and solution composition. Many geothermal waters contain high concentrations of arsenic. Natural arsenic in ground water at concentrations above the drinking water standard of $10 \mu \mathrm{g} /$ liter is not uncommon ${ }^{6}$.

Probiotics strains are natural components of the human oral and intestinal microflora and are ubiquitous within the environment making the overall risk of infection by these species low. Hence many members of the Lactobacillus genus have obtained the generally recognized as safe status for use in food in the United States and European Food Safety Authority (EFSA).

Lactobacillus is the most commonly used as probiotics ${ }^{7}$. The use of probiotics in food products as well as a standalone therapy is very attractive, as they present an effective and noninvasive approach to providing health benefits, such as reducing inflammation.

Arsenicosis or chronic exposure leads to hypertension, cardiovascular diseases, developmental abnormalities, diabetes, hearing loss, hematological, neurological, reproductive problem, black foot diseases and cancer. This may affect a number of organs lungs, kidney, bladder, liver, testis, uterus and prostate gland ${ }^{\mathbf{8}}$.

Therefore the study is designed to evaluate In Vivo elimination of arsenic through Lactobacillus sporogenes in mice.

\section{Materials and Methods:-}

Arsenic:-

In the present study Sodium Arsenate (Merck, Mumbai) was used for experiment.

\section{Microbes Used:-}

Lactobacillus sporogenes was used as antidote.

\section{Experimental model:-}

Swiss albino mice (Mus musculus) weighing 30 $22 \mathrm{gm}$ were selected as an experimental model in the present study. All experimental procedures were conducted as per the guidelines of CPCSEA (Committee for the Purpose of Control and Supervision of Experiments on Animals). Ethical approval was obtained from Institutional Animal Ethics Committee of the institute.

\section{Methodology:-}

\section{Chronic Toxicity Study:-}

Selected pathogen-free mice were sorted and sodium arsenate was administered at $6 \mathrm{mg} / \mathrm{kg}$ body weight dose for 4 weeks by Gavage method. Sacrifices were done at the end of $2^{\text {nd }}$ week and $4^{\text {th }}$ week of Sodium arsenate administration in each group.

\section{Bioremediation:-}

Sodium arsenate administration at $6 \mathrm{mg} / \mathrm{kg}$ b.wt for 4 weeks was followed by the administration of Lactobacillus sporogenes for 8 weeks at 50 thousand spores $/ \mathrm{kg}$ body weight. Animals were sacrificed on $4^{\text {th }}$ week and $8^{\text {th }}$ week of microbial administration.

\section{Histopathological Studies:-}

Mice were sacrificed from each group for histological analysis. The kidney tissue were dissected out and washed three times in isotonic saline $(0.85 \mathrm{w} / \mathrm{v} \%)$, fixed in $10 \%$ neutral formalin solution and was processed. Slides were stained with Hematoxylene-Eosin (H \& E) stains and examined under light microscope.

\section{Biochemical and Hormonal Assessment:-}

Blood were collected by orbital puncture and centrifuged to separate the serum to carry out biochemical analysis. Biochemical analysis were performed through serum by standard kit process (Coral crest) through U.V vis spectrophotometer. 


\section{Results:-}

Biochemical assay:-

Kidney function test were analyzed in different study group. In control group urea level were $16.50 \pm 0.28 \mathrm{mg} / \mathrm{dl}$ while after two weeks and four weeks arsenic administered group it become $33.78 \pm 0.15 \mathrm{mg} / \mathrm{dl}$ and $38.65 \pm 0.32$ $\mathrm{mg} / \mathrm{dl}$. While in arsenic four weeks administered group followed by Lactobacillus four weeks and eight weeks administered group it was $35.50 \pm 0.28 \mathrm{mg} / \mathrm{dl}$ and $37.00 \pm 0.57 \mathrm{mg} / \mathrm{dl}$ respectively. (Graph: I).

\section{Graph - I: Urea in serum of mice}

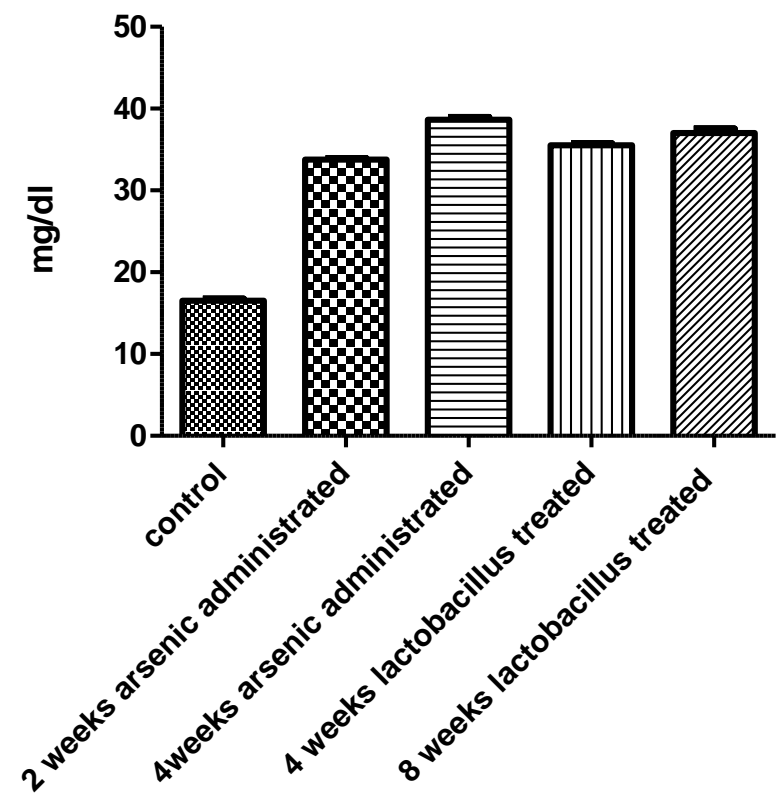

In control group uric acid level were $4.233 \pm 0.14 \mathrm{mg} / \mathrm{dl}$ while after two weeks and four weeks arsenic administered group it become $7.407 \pm 0.22 \mathrm{mg} / \mathrm{dl}$ and $8.837 \pm 0.076 \mathrm{mg} / \mathrm{dl}$. While in arsenic four weeks administered group followed by Lactobacillus four weeks and eight weeks administered group it was $7.100 \pm 0.15 \mathrm{mg} / \mathrm{dl}$ and $6.267 \pm$ $0.31 \mathrm{mg} / \mathrm{dl}$ respectively. (Graph: II).

\section{Graph - II: Uric acid in serum of mice}

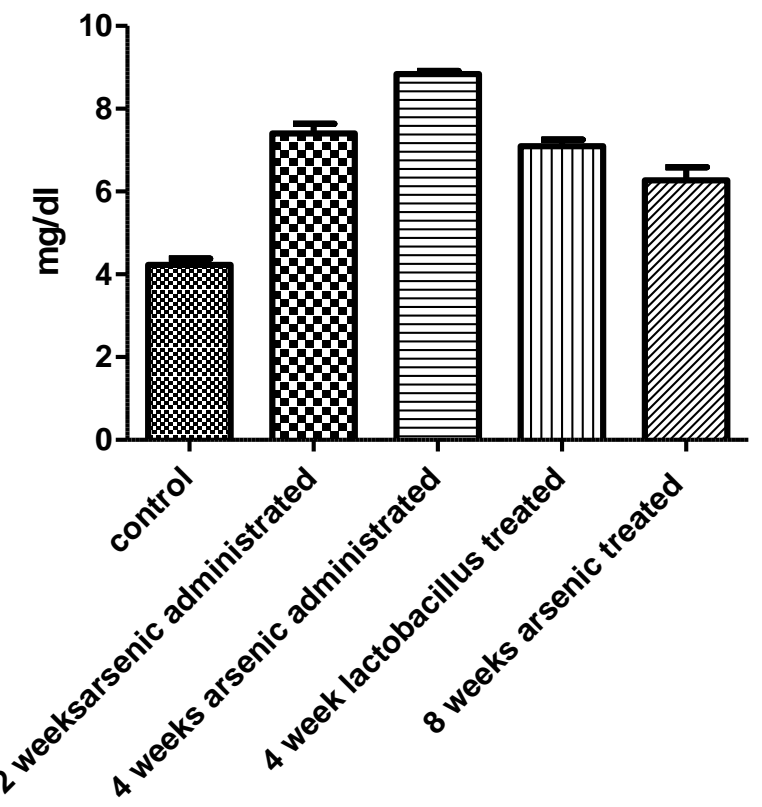




\section{Histological study:-}

Kidney tissues were studied in detailed in different groups. In control group of mice glomerulus, bowmens capsule, proximal convoluted tubule and distal convoluted tubule were normal with well defined cytoplasm and nuclear material (Figure: 1).

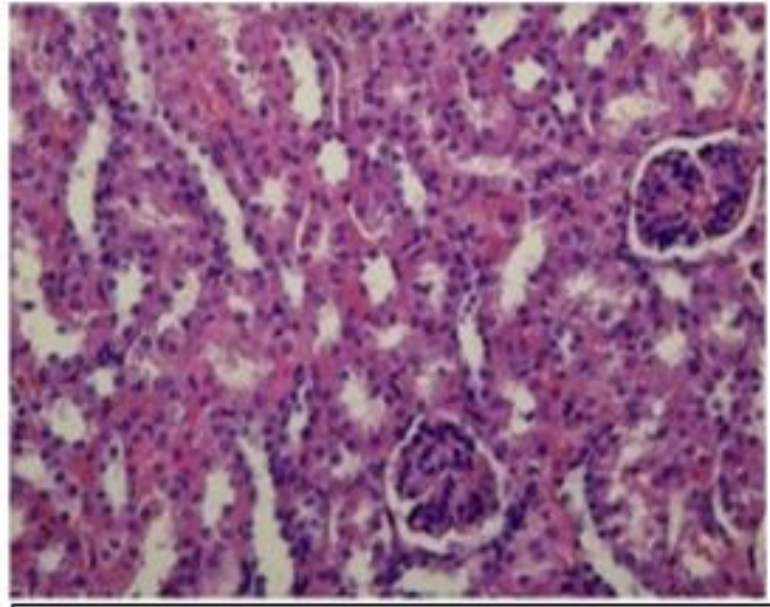

Figure - 1: showing kidney of control mice with normal glomerulus, bowmens capsule, proximal convoluted tubule and distal convoluted tubule. Well defined cytoplasm and nuclear material were observed.

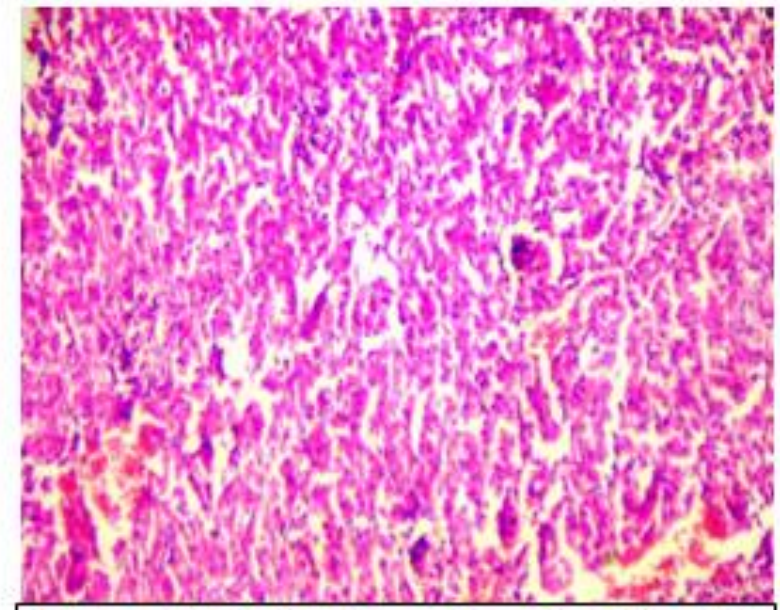

Figure -2 : showing kidney of arsenic eight weeks administerd group with many vacuolated spaces. Clustered nuclei were also observed in glomerulus. Degenerated cytoplasm were observed in tubules of PCT and DCT. Bowmens capsule were also degenerated.

In arsenic eight weeks administered group many vacuolated spaces were observed. Clustered nuclei were also observed. Degenerated cytoplasm was observed in tubules of PCT and DCT. Bowmens capsule was observed in degenerated condition with clustered nuclei in glomerulus (Figure: 2). In arsenic eight weeks followed by Lactobacillus four weeks administered group show restoration in glomerulus and bowmens capsule. PCT and DCT were also restored in structure to greater extent (Figure: 3). In arsenic eight weeks followed by Lactobacillus eight weeks administered group show restoration in cytoplasm of PCT and DCT. Least vacuolization were observed. Well defined bowmens capsule and glomerulus were observed (Figure: 4).

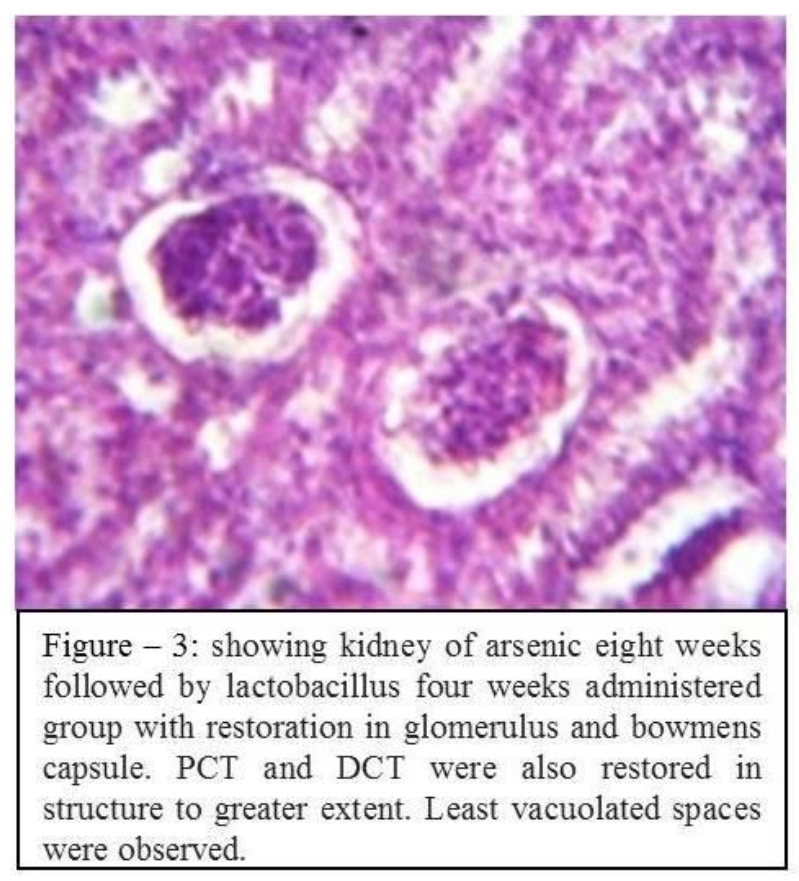

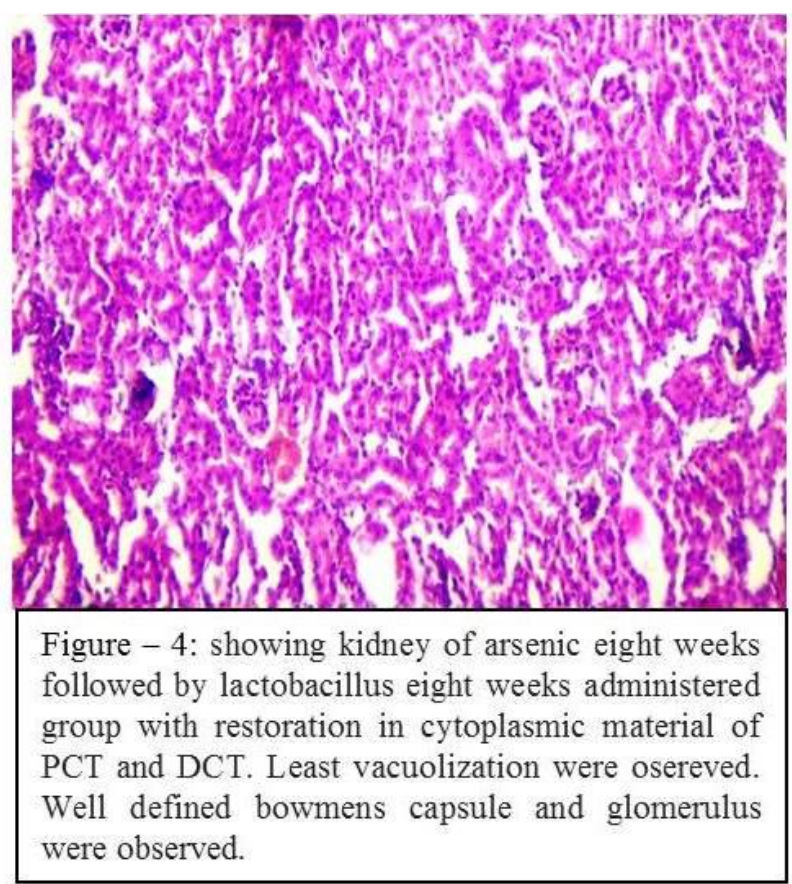




\section{Discussion:-}

Exposure to arsenic imposes a big health issue worldwide'. Arsenical keratosis appears as a diffuse thickening involving palm and soles alone or in combination with nodules in severe cases crack may be seen in the soul ${ }^{10}$. Oxidative DNA damage, acquired tolerance to apoptosis, enhanced cell proliferation, altered DNA methylation, genomic instability and aberrant estrogen signaling have been reported to be involved in liver toxicity caused by $\operatorname{arsenic}^{11}$. Arsenic exposure also causes spontaneous abortion, still births, reduced birth weight, and infant mortality ${ }^{12}$. Kidney leads to oxidative phospholipids degradation, arsenic induce peroxidation in kidney induces oxidative damage leading to functional deterioration ${ }^{13}$. In our study we observed elevated level of urea and uric acid in arsenic exposed group. Glomerulus and Bowmans capsules were also degenerated to greater extent. Proximal convoluted tubule and distal convoluted tubule were degenerated to greater extent.

Since the cell wall of gram positive bacteria has higher metal binding activity ${ }^{14}$. The uptake of arsenic by bacteria via glycerol and phosphate transport system, once arsenic has entered the cell, other defense mechanisms are activated. These mechanisms are based on energy dependent efflux of arsenite from cell. Lactobacillus has also mar and ars operon system ${ }^{15}$ which encode efflux transpoter which have ability to export metals out of their cell reduce damage to organism by lowering the concentration. The mechanisms by which Probiotics exert their effects are largely unknown, but may involve modifying gut $\mathrm{pH}$, antagonizing pathogens through production of antimicrobial compounds, stimulating immunomodulatory cells, and producing lactase ${ }^{\mathbf{1 6}}$. Cell wall of lactic acid bacteria is seems to be contain a large number of negatively charged functional groups, mainly carboxyl and phosphoryl. Electrophoratic studies have established that the net surface charge of lactic acid bacteria is negative at neutral $\mathrm{pH}^{17}$, $\mathbf{1 8 , 1 9 , 2 0}$. In present study, we observed restoration in urea and uric acid. Since arsenic has negatively charged species and this is problematic for bacterial binding interaction therefore overcome surface negative charge by methylatating a selection of lactobacilli in order to neutralize the negative surface charge to foster more attraction between positively charged amino group on the cell wall and negative charged metals. Peptidoglycan layer and surface proteins, such as S-layer proteins, are known to contain positively charged groups. Lactobacillus acidophilus strains and Lactobacillus crispatus DSM20584 are known to produce S-layer proteins, which may explain their activity against arsenic ${ }^{21}$. In the present study restoration in nuclear and cytoplasmic material of Bowmans capsule and glomerulus were observed. Effective restoration was also observed in tubular system of kidney.

Escherchia coli uptake arsenic by non-specific phosphate transpoter pit, some other bacteria has more specific phosphate transporter pit which transport arsenic less specific ${ }^{22}$ 23. Probably water is absorbed in large intestine and this Lactobacillus also resides there. Arsenic is absorbed through walls of Lactobacillus and eliminated with them. In this way it is eliminated from mice and reduced arsenic induced nephrotoxicity were observed in them.

\section{Conclusion:-}

Therefore from the above study it is concluded that Lactobacillus causes in vivo elimination of arsenic from mice. It acts well against arsenic toxicity in mice and restores biochemical parameters effectively. It also maintains normal architecture of kidney tissues. Lactobacillus reduces nephrotoxicity caused by arsenic exposure effectively. In this way it will be the most effective for in vivo elimination of arsenic induced toxicity in mice.

\section{References:-}

1. Mukherjee A, Sengupta M.K, Hossain M.Amir, Sad Ahamed, Das Bhasker, Nayak.B, Dilip Lodh, Rahman M.M, and Chakrabort. D (2006) Arsenic Contamination in Groundwater: A Global Perspective with Emphasis on the Asian Scenario, J HEALTH POPUL NUTR (2):142-163.

2. Sushant K. and Singh N. V. (2014), Mapping composite vulnerability to groundwater arsenic contamination: an analytical framework and a case study in India Springer Science;Business Media Dordrecht

3. Mukherjee A, Sahab D, F. H Charles, G.T.Richard, Ahmede K.M, Bhanjan N.S(2015) Groundwater systems of the IndianSub-ContinentAbhijit, Journal of Hydrology: Regional Studies(58)1-14

4. Kumar P, Ram Avtar P Kumar.A, Kumar S C.K, Parijat T G, Kumar. S Ramanathan A.L(2014) Geophysical approach to delineate arsenic hot spots in the alluvialaquifers of Bhagalpur district, Bihar (India) in the central Gangetic plainsAppl Water Sci, 4:89-97

5. Chaurasia. N, Mishra. A and S K Pandey (2012) Finger Print of Arsenic Contaminated Water in India-A Review Forensic Res(3):1-4,

6. Kirk. D and D. Nordstrom ( 2002); Worldwide Occurrences of Arsenic in Ground Water; 296, 2143 
7. Zoghia A, DaranibK.K and Sohrabvandib.S (2014) Surface Binding of Toxins and Heavy Metals by Probiotics Mini-Reviews in Medicinal Chemistry, 14, 84-98

8. Muthumani M; (2013) Tetrahydrocurcumin Potentially Attenuates Arsenic Induced Oxidative Hepatic Dysfunction in Rats, clinical toxicology (3:4),1-10

9. Shankar S, Shanker U, and Shikha (2014) Arsenic Contamination of Groundwater: A Review of Sources,Prevalence, Health Risks, and Strategies for . Mitigation,Hindawi Publishing Corporation (14) 1-18.

10. Guha D.N \& Mazmudr (2008); chronic arsenic toxicity \& human health Indian J Med Res 128, pp 436-447.

11. Gaim K, Girmay Gebru, Sunday Abba (2015); The Effect of Arsenic on Liver Tissue of Experimental Animals (Fishes and Mice), - A Review article (5),1-9.

12. Allan H. Smith and Craig M. Steinmaus (2009) Health Effects of Arsenic and Chromium in Drinking Water: RecentHuman Findings Annu Rev Public Health

13. Noman A.S.M, Dilruba S, Mohanto N.C, Rahman L, Zohora Khatun Z, Riad W and Abdullah Al Mamun Shahnur AlamA.A.S, Sharmin Aktar.S Chowdhury. S, Zahangir Alam.Z, Saud Zillur Rahman.S.Z and Hossain.K(2015), cytology and histology 6;3,1-5.

14. Ibrahim, F., T. Halttunen, R. Tahvonen, and S. Salminen. (2006). Probiotic bacteria as potential detoxification tools: assessing their heavy metal binding isotherms. Can. J. Microbiol. 52:877-885.

15. Osborn AM, Bruce KD, Strike P, Ritchie DA. (1997). Distribution, diversity and evolution of the bacterial mercury resistance (mer) operon. FEMS Microbiol. Rev. 19:239-262

16. Khairy M.A. Zoheir, Amro A. Amara , S.F. Ahmad, Mahmoud A. Mohammad, Abdelkader E. Ashour, Gamaleldin I. Harisa Adel R. Abd-Allah (2014) Study of the therapeutic effects of Lactobacillus and a-lipoic acid against dimethylnitrosamine-induced liver fibrosis in rats, Journal of Genetic Engineering and Biotechnology ELSEVIER 12,135-142

17. Halttunen T, Finell M., Salminen S. (2007) Arsenic removal by native and chemically modified lactic acid bacteria. International Journal of Food Microbiology 120(1-2):173-178.

18. Jafarei P, and Maryam T E, (2011) lactobacillus acidophilus cell structure and application, African journal of microbiology research Vol.5(24),pp.4033-4042

19. Sengupta. R, Altermann. E, Rachel C. Anderson, Warren C. McNabb, Paul J. Moughan, and Nicole C. Roy, (2013) The Role of Cell Surface Architecture of Lactobacilli in Host-Microbe Interactions in the Gastrointestinal Tract: Hindawi Publishing Corporation, Mediators of Inflammation Volume 2013, Article ID 237921, 16 pages http://dx.doi.org/10.1155/2013/237921

20. Hynönen.U \& Airi Palva.A(2013) Lactobacillus surface layer proteins: structure, function and applications Appl Microbiol Biotechnol 97:5225-5243.

21. Monachese.M, Jeremy P. Burton, and Reida.G (2012), Bioremediation and Tolerance of Humans to Heavy Metals through Microbial Processes: a Potential Role for Probiotics,American society for microbiology (78) 6397-6404.

22. Drewniak.L \& A.sklodowska.A (2013) Arsenic-transforming microbes and their role in biomining processes, Environ Sci Pollut Res 20:7728-7739).

23. Kruger.M.C \& Philippe N. Bertin \& Hermann J. Heipieper \& Florence Arsène-Ploetze (2013) Bacterial metabolism of environmental arsenic-mechanismsand biotechnological applications Appl Microbiol Biotechnol 97:3827-3841. 